\title{
RVX 208
}

Abstract

\section{Introduction}

Resverlogix is developing RVX 208, an orally available, small-molecule therapeutic that increases apolipoprotein AI (ApoA-I) and high-density lipoprotein (HDL) cholesterol levels, to treat cardiovascular disorders, including atherosclerosis, cerebrovascular disease (i.e. stroke), and hypertension. The first-in-class compound could also be beneficial for the treatment of Alzheimer disease (AD). Clinical development is underway in the US for atherosclerosis, acute coronary syndromes and AD.

RVX 208 emerged from Resverlogix's cardiovascular research programme.

Reverse cholesterol transport (RCT) is a pathway by which cholesterol is transported from the artery wall to the liver for excretion, thereby reducing the progression of atherosclerosis. HDL and ApoA-I are major constituents of the RCT pathway; acting as acceptors for cholesterol molecules. A key component of RCT is cholesterol efflux, in which accumulated cholesterol is removed from macrophages. RVX 208 increases endogenous ApoA-I production, which raises HDL levels and enhances HDL functionality to augment RCT. Previous landmark trials supported the concept that ApoA-I enhancement in humans reversed atherosclerotic plaque volume in major coronary arteries. RVX 208 was discovered by Resverlogix using its NexVas ${ }^{\mathrm{TM}}$ technology.

Additionally, emerging evidence from large epidemiology studies, such as the Harvard Women's Study, the Honolulu-Asia Aging Study and the Whitehall II study, are building support for the relationship between poor HDL and ApoA-I levels, and decreased cognitive function and AD. Researchers investigating elective HMG-CoA reductase inhibitor (statin) use and fractionated cholesterol levels in the ADAPT cohort have identified a significant relationship between elevated HDL levels and better performance on the Mini Mental State Examination (MMSE), and a significant inverse relationship between increased total and low-density lipoprotein (LDL) cholesterol and learning and memory. Elevated cholesterol levels are thought to increase the production and accumulation of the putative $\mathrm{AD}$ neurotoxin,

This summary has been extracted from Wolters Kluwer's $R \& D$ Insight drug pipeline database. $R \& D$ Insight tracks and evaluates drug development worldwide through the entire development process, from discovery, through preclinical and clinical studies to market launch. This is an open access article published under the terms of the Creative Commons License "Attribution-NonCommercial-NoDerivative 3.0" (http://creativecommons.org/ licenses/by-nc-nd/3.0/) which permits non-commercial use, distribution, and reproduction, provided the original work is properly cited and not altered. 
amyloid-beta $(A \beta)$, which is an important marker of cognitive function and AD. ${ }^{[1]}$

Resverlogix has entered into discussions with various leading life science organisations for the NexVax ${ }^{\mathrm{TM}}$ PR cardiovascular technology programme. At the 2009 European Society of Cardiology Congress meeting in Barcelona, Spain, Resverlogix communicated the results for the 28day phase Ib/IIa trial of RVX 208 to potential partners under a confidentiality agreement. ${ }^{[2]}$

\subsection{Company Agreements}

In January 2005, Resverlogix began an international research collaboration with the Cedars-Sinai Medical Center and Dr PK Shah, Director of the Atherosclerosis Research Center. ${ }^{[3]}$ The programme was expanded in July 2005 to include the acute as well as the chronic aspects of cardiovascular disorders, as a result of favorable preclinical testing. ${ }^{[4]}$

Resverlogix established RVX Therapeutics in July 2005, a wholly owned subsidiary for business and strategic objectives. Resverlogix retains its primary asset, the NexVas ${ }^{\mathrm{TM}}$ technology, while RVX Therapeutics holds non-core assets including TGF-Beta Shield ${ }^{\mathrm{TM}}$ technology. ${ }^{[5]}$

\subsection{Key Development Milestones}

\subsubsection{Alzheimer Disease (AD)}

Resverlogix has conducted an exploratory phase Ia trial to evaluate RVX 208 (2, 3, and $8 \mathrm{mg} / \mathrm{kg}$ ) for the treatment of AD. This doubleblind, dose-escalation, placebo-controlled trial enrolled 24 subjects in three separate dosing cohorts for a period of 7 days. Plasma levels of $A \beta_{40}$ were measured on days 1 and 7. Post hoc analysis revealed a $12-14 \%$ increase in plasma $A \beta_{40}$ levels at the highest dose of RVX $208(8 \mathrm{mg} / \mathrm{kg})$ after 7 days of dosing. Based on the study hypothesis, these results trended towards significance versus placebo, even with the minimal number of study subjects. ${ }^{[1,6]}$

RVX 208 has also demonstrated positive effects on plasma $A \beta_{40}$ levels in 299 patients with stable coronary artery disease (the phase II ASSERT trial population). After 12 weeks of treatment with RVX 208, $150 \mathrm{mg}$ twice daily, a highly significant change from baseline and $13.4 \%$ change compared with placebo was observed in the quartile of patients with the lowest plasma $A \beta_{40}$ levels at baseline, which is known to increase the risk for developing AD. Resverlogix announced that the data further supports the previous phase I trial in AD and the hypothesis that RVX 208 can augment $A \beta_{40}$ transport from the brain. ${ }^{[7]}$

\subsubsection{Cardiovascular Disorders (Acute Coronary Syndrome and Atherosclerosis)}

In October 2010, Resverlogix and the Cleveland Clinic in the US completed a phase II, randomized, placebo-controlled, dose-ranging trial (ASSERT; NCT01058018) of RVX 208 for the treatment of atherosclerosis in 299 patients with stable coronary artery disease. The trial was initiated in December 2009. The primary endpoint was the change in ApoA-I levels after 3 months of dosing. Patient recruitment was completed in February 2010, and dosing was completed in May 2010 (5 months ahead of schedule, and without any dose alterations) ${ }^{\left[{ }^{[8]}\right.}$ Results were presented in November 2010. ${ }^{[9-13]}$

Resverlogix announced in September 2010 that it had made important modifications to the design of its phase IIb trial of oral RVX 208 (RVX222-CS-007; ASSURE 1; NCT01067820). Primary changes to the trial included increasing the number of patients from 120 to over 230, making all patients undergo an intravascular ultrasound (IVUS) assessment, increasing the number of trial sites and opening recruitment to multiple countries, the inclusion of patients with low HDL-cholesterol levels and changing the primary endpoint to plaque regression. The trial was expected to begin dosing before the end of 2010.[14] However, Resverlogix temporarily suspended the trial in order to modify enrollment procedures to expedite recruitment. ${ }^{[10]}$ The trial was underway in the US and was investigating the early effects of oral RVX 208 (100 or $150 \mathrm{mg}$ twice daily for 2 weeks) on the changes in lipid and coronary plaque in patients with recent acute coronary syndrome. The ASSURE 1 study complements the ASSERT trial in patients with stable coronary artery disease. ${ }^{[15,16]}$

In August 2009, Resverlogix completed a doubleblind, placebo-controlled, US-based, phase Ib/IIa 
trial (RVX222-CS-003; NCT00768274) investigating the safety, pharmacokinetics and pharmacodynamics of three dosages of RVX 208 in 72 subjects with normal and low HDL levels. Positive results reported from this 28-day trial showed RVX-208 increased plasma levels of ApoA-I by $13.25 \%$ compared with placebo in patients with baseline HDL/ApoA-I. ${ }^{[2,17-21]}$

Resverlogix has completed two arms of a phase I trial investigating the bioequivalence of RVX 208 capsules and the original powder formulation. The final arm was expected to be completed by the end of the third quarter of 2009. ${ }^{[2]}$

A phase Ia safety, tolerability, and pharmacokinetics study has successfully met its objectives, being well tolerated and showing good oral absorption. The three-armed study comprised a single escalating dose portion, a food versus fasted effect on pharmacokinetics portion, and three cohorts with 7-day multiple dosing arms. The trial took place at a US contract research organisation and enrolled 80 healthy volunteers. Results concerning the effect of RVX 208 on levels of HDL-cholesterol have been reported. ${ }^{[22-26]}$

Data from the 80th and 81st Scientific Sessions of the American Heart Association demonstrated that oral administration of RVX 208 increased the production of serum ApoA-I levels and im- proved HDL-mediated cholesterol efflux in African Green Monkeys. ${ }^{24,27,28]}$

As of April 2008, RVX 208 had undergone 126 preclinical trials comprising safety, toxicity, pharmacokinetics, and pharmacology studies. ${ }^{[25]}$

RVX 208 has shown efficacy in raising ApoA-I production and HDL levels in human trials and also reduced plaque numbers in a mouse model of atherosclerosis. ${ }^{[29]}$

The US FDA approved an IND (investigational new drug) for a phase I trial of RVX 208 for the treatment of cardiovascular disorders in December 2007. ${ }^{[30]}$

\subsection{Patent Information}

In November 2010, Resverlogix filed a patent application covering dosing combinations of RVX 208 and leading statin therapeutics. The patent includes data from the ASSERT trial showing that RVX 208 at certain doses in combination with statins markedly improved not only ApoA-I production, HDL, and large HDL particles, but also important properties of LDL and ApoB particles. The synergistic effect of RVX 208 was more pronounced with Pfizer's Lipitor ${ }^{\circledR}$ and AstraZeneca's Crestor ${ }^{\circledR} \cdot{ }^{[31]}$

Resverlogix, on behalf of RVX Therapeutics, announced the filing of a patent application covering $\mathrm{NexVas}^{\mathrm{TM}}$, its cardiovascular technology.

Table I. Features and properties

\begin{tabular}{|c|c|}
\hline Alternate names & RVX 000222; RVX-208 \\
\hline Originator & Resverlogix Corporation \\
\hline Highest development phase & II (USA) \\
\hline Active development indications & Acute coronary syndromes, Alzheimer disease, Atherosclerosis \\
\hline Class & Quinazolines, Small-molecules \\
\hline Mechanism of action & Apolipoprotein A I stimulants \\
\hline CAS Registry Number & $1246400-89-4$ \\
\hline Route of Administration & Oral \\
\hline Pharmacodynamics & $\begin{array}{l}\text { Significantly increases pre-beta high density lipoprotein (HDL), cholesterol efflux, and serum } \\
\text { apolipoprotein A-I in healthy volunteers; significantly increases average serum apolipoprotein A-I (ApoA-I) } \\
\text { and HDL-cholesterol levels in African Green monkeys; increases plasma levels of Apo-Al and HDL } \\
\text { particles in humans }\end{array}$ \\
\hline \multicolumn{2}{|l|}{ ATC Codes } \\
\hline WHO ATC code & C (Cardiovascular System), C10 (Lipid Modifying Agents), N06D (Anti-Dementia Drugs) \\
\hline EphMRA ATC code & $\begin{array}{l}\text { C (Cardiovascular System), C10 (Lipid-Regulating/Anti-Atheroma Preparations), N7D (Anti-Alzheimer } \\
\text { Products) }\end{array}$ \\
\hline
\end{tabular}


Table II. History

\begin{tabular}{|c|c|c|c|}
\hline Event Date & Update Type & Comment & Update Date \\
\hline 2 February 2011 & InThought Forecasts & inThought Analysis for atherosclerosis updated & 2 February 2011 \\
\hline 25 January 2011 & Scientific Update & $\begin{array}{l}\text { Pharmacodynamics data from a phase II trial in } \\
\text { atherosclerosis/acute coronary syndromes that support ongoing } \\
\text { development in Alzheimer disease released by Resverlogix }{ }^{[7]}\end{array}$ & 28 January 2011 \\
\hline 17 November 2010 & Scientific Update & $\begin{array}{l}\text { Pharmacodynamics data from the phase II ASSERT trial in } \\
\text { atherosclerosis presented at the } 83 \text { rd Annual Scientific Sessions } \\
\text { of the American Heart Association (AHA-2010 })^{[9]}\end{array}$ & 22 November 2010 \\
\hline 7 October 2010 & Trial Update & $\begin{array}{l}\text { Resverlogix completes the phase II ASSERT trial for } \\
\text { atherosclerosis in the US (NCT01058018) }\end{array}$ & 16 February 2011 \\
\hline 23 June 2010 & Scientific Update & $\begin{array}{l}\text { Pharmacodynamics and adverse events data from a phase la/llb } \\
\text { trial in volunteers with normal or low HDL-cholesterol released by } \\
\text { Resverlogix }{ }^{[17,32]}\end{array}$ & 24 June 2010 \\
\hline 12 May 2010 & Trial Update & $\begin{array}{l}\text { Resverlogix suspends enrolment in the phase II ASSURE } 1 \text { trial for } \\
\text { acute coronary syndromes in the US }{ }^{[10]}\end{array}$ & 14 May 2010 \\
\hline 25 February 2010 & Trial Update & $\begin{array}{l}\text { Resverlogix initiates enrollment in the phase II ASSURE } 1 \text { trial for } \\
\text { acute coronary syndromes in the US }\end{array}$ & 15 March 2010 \\
\hline 9 February 2010 & Trial Update & $\begin{array}{l}\text { Resverlogix completes enrollment in the ASSERT trial for } \\
\text { atherosclerosis in the US (NCT01058018) }\end{array}$ & 10 February 2010 \\
\hline 22 December 2009 & Phase Change & Phase II clinical trials in atherosclerosis in the US (PO) & 15 March 2010 \\
\hline 22 December 2009 & Phase Change & Phase II clinical trials in acute coronary syndromes in the US (PO) & 15 March 2010 \\
\hline 29 September 2009 & Scientific Update & $\begin{array}{l}\text { Final pharmacodynamics, pharmacokinetic and adverse events } \\
\text { data from a phase la/llb trial in volunteers with normal or low } \\
\text { HDL-cholesterol released by Resverlogix Corporation }{ }^{[18]}\end{array}$ & 2 October 2009 \\
\hline 25 August 2009 & Scientific Update & $\begin{array}{l}\text { Interim pharmacodynamics data from a phase lb/lla trial in } \\
\text { volunteers with normal or low HDL-cholesterol released by } \\
\text { Resverlogix }{ }^{[2]}\end{array}$ & 31 August 2009 \\
\hline 25 August 2009 & Trial Update & $\begin{array}{l}\text { Resverlogix completes a phase } \mathrm{lb} / \mathrm{ll} \text { a trial in subjects with normal or } \\
\text { low HDL-cholesterol levels in the US }\end{array}$ & 31 August 2009 \\
\hline 31 March 2009 & Scientific Update & $\begin{array}{l}\text { Interim pharmacodynamics data from a phase I trial in } \\
\text { cardiovascular disorders presented at the 58th Annual Scientific } \\
\text { Session of the American College of Cardiology (ACC-2009) })^{[22]}\end{array}$ & 1 April 2009 \\
\hline 10 November 2008 & Scientific Update & $\begin{array}{l}\text { Pharmacodynamics data from a phase la and a preclinical trial in } \\
\text { cardiovascular disorders presented at the } 81 \text { st Annual Scientific } \\
\text { Sessions of the American Heart Association (AHA-2008) }{ }^{[24]}\end{array}$ & 14 November 2008 \\
\hline 10 November 2008 & Phase Change & Phase I clinical trials in Alzheimer disease in the US (PO) & 13 November 2008 \\
\hline 21 October 2008 & Trial Update & $\begin{array}{l}\text { Resverlogix advances RVX } 208 \text { to the second arm of a phase } \mathrm{lb} / \mathrm{lla} \\
\text { trial in the US }\end{array}$ & 23 October 2008 \\
\hline 30 September 2008 & Phase Change & Phase-I/II clinical trials in cardiovascular disorders in the US (PO) & 23 October 2008 \\
\hline 18 June 2008 & Scientific Update & $\begin{array}{l}\text { Interim pharmacodynamics data from a phase I trial in } \\
\text { cardiovascular disorders released by Resverlogix }{ }^{[33]}\end{array}$ & 20 June 2008 \\
\hline 22 April 2008 & Trial Update & $\begin{array}{l}\text { Resverlogix completes dosing in its phase la trial for cardiovascular } \\
\text { disorders in the US }\end{array}$ & 30 April 2008 \\
\hline 14 January 2008 & Phase Change & Phase I clinical trials in cardiovascular disorders in the US (PO) & 16 January 2008 \\
\hline 10 December 2007 & Regulatory Status & $\begin{array}{l}\text { The US FDA approves IND application to begin phase I trial of RVX } \\
208 \text { in cardiovascular disorders (PO) }\end{array}$ & 1 May 2008 \\
\hline 29 November 2006 & Phase Change & Preclinical trials in cardiovascular disorders in the US (PO) & 30 April 2008 \\
\hline
\end{tabular}




\section{Scientific Summary}

\section{1 Pharmacokinetics}

Oral administration of RVX 208 resulted in dose dependant pharmacokinetic parameters; the drug was given at either low $(2 \mathrm{mg} / \mathrm{kg})$, doseescalating $(3-6 \mathrm{mg} / \mathrm{kg})$, or high $(6 \mathrm{mg} / \mathrm{kg})$ doses for a 28 days. ${ }^{[18]}$

\subsection{Adverse Events}

RVX 208 was demonstrated to be safe and well tolerated in a phase Ib/IIa study. ${ }^{[17,18,32]}$

\subsection{Pharmacodynamics}

\subsubsection{AD and Cognition Disorders}

RVX 208 demonstrated positive effects on plasma $\mathrm{A} \beta_{40}$ levels in 299 patients with stable coronary artery disease (the phase II ASSERT trial population). After 12 weeks of treatment with twice-daily RVX $208150 \mathrm{mg}$, a highly significant $34.8 \mathrm{pg} / \mathrm{mL}$ change from baseline and $13.4 \%$ change compared with placebo was observed in the quartile of patients with the lowest plasma $A \beta_{40}$ levels at baseline, which is known to increase the risk for developing AD. ${ }^{[7]}$

\subsubsection{Hyperlipidemia}

Clinical Studies: Results from the phase II ASSERT trial showed dose dependent increases in ApoA-I by $5.6 \%$, statistically significant increases in HDL-cholesterol including alpha1 particles or functional HDL by $8.3 \%$, and large HDL particles by $21.1 \%$. ApoA-I and other HDL particles continued to increase at the end of the 12-week study. ${ }^{[9]}$

Results from a phase Ib/IIa study (NCT00768274) conducted in 72 patients with normal or low HDL-cholesterol levels demonstrated RVX 208 to be associated with a significant increase in ApoA-I levels. The primary endpoint, plasma ApoA-I increase compared to placebo, achieved a range of $5.1-10.4 \%$ in all patients at all doses at days 8 and 28, respectively. At the lowest dose of $1 \mathrm{mg} / \mathrm{kg}$ twice daily in patients with low levels of HDL-cholesterol, significantly increased plasma ApoA-I levels by $5.7 \%$ and $7.8 \%$ at days 8 and 28 , respectively $(\mathrm{p}<0.05)$. A critical RCT functionality marker, alpha-1 HDL particles, also demonstrated significance with an increase of $46.7 \%(\mathrm{p}<0.004)$ in all patients and $57.2 \%(\mathrm{p}<0.02)$ in the low dose arm over placebo at day 28. RVX 208 was shown to be compatible with simvastatin $(40 \mathrm{mg}) .^{[2,17,18,32]}$

An interim analysis of 24 healthy volunteers who participated in a 7-day phase I trial of RVX 208 showed statistically significant improvements over placebo in three of the four key variables assessed. Significant improvements included increases in pre-beta HDL of $42 \%$, cholesterol efflux of $11 \%$, and serum ApoA-I of $11 \%$. A fourth variable, HDL-cholesterol level, increased by $10 \%$ but the change was not significant. A rapid onset of action was observed, with the serum ApoA-I increases surpassing the previous $8 \%$

Table III. Forecasts

\begin{tabular}{|c|c|c|c|}
\hline \multicolumn{4}{|c|}{ InThought Probability of Approval ${ }^{a}$} \\
\hline Indication & Approval Date Estimate & inThought Approvability Index & Last Update \\
\hline Acute coronary syndromes & $\mathrm{NE}$ & $24 \%$ (NYR) & 21 May 2010 \\
\hline Alzheimer disease & NE & $19 \%$ (NYR) & 27 Jul 2009 \\
\hline Atherosclerosis & 1 Apr 2014 & $15 \%(\mathrm{~F})$ & 2 Feb 2011 \\
\hline \multicolumn{4}{|c|}{$\begin{array}{l}\text { a The Wolters Kluwer Health Approvability Index is a dynamic tool that assesses the progress of a drug candidate through clinical } \\
\text { development, evaluating strength of clinical data and trial design, benchmarked against historical parameters and likelihood to maintain } \\
\text { forward momentum. Points are assigned for specific line items relating to safety, efficacy, and other factors in each phase of clinical } \\
\text { development. Possible points total } 100 \text { upon drug approval, and are allocated in each phase according to the historical approval rate of } \\
\text { similar drugs, such that the current points of a drug relate to its probability of approval. In addition, a letter grade is assigned and reflects the } \\
\text { momentum of a drug candidate in its current phase, with 'A' indicating significantly above average/likely to progress, 'C' indicating average, } \\
\text { and 'F' indicating significantly below average/unlikely to progress. 'NYR' stands for 'Not Yet Rated,' indicating that the probability of } \\
\text { approval is based on historical approval rates for similar drugs according to indication, molecule type, novelty, and phase, but without } \\
\text { analyses of clinical data, trial design, and other factors specific to the individual agent. }\end{array}$} \\
\hline
\end{tabular}


5-week average benchmark totals displayed by the ApoA-I milano agent developed by Pfizer. ${ }^{[22,33]}$ RVX 208 was dosed at 2, 3, or $8 \mathrm{mg} / \mathrm{kg} /$ day. Further analysis of the data revealed that after 7 days, RVX 208 increased the change for ApoAI by $11 \%$ versus placebo $(p=0.03)$. The corresponding pre-beta HDL change was $42 \%(\mathrm{p}=0.007)$ versus placebo. This change correlated with ABCA1-dependent cholesterol efflux change, which increased by $10 \%(\mathrm{p}=0.03) .{ }^{[23,24]}$

Preclinical Studies: Highly significant increases in average serum ApoA-I and HDL-cholesterol levels (57\% and $92 \%$, respectively) occurred in African Green monkeys that received RVX 208 $(7.5,15$, and $30 \mathrm{mg} / \mathrm{kg}$ twice daily and $60 \mathrm{mg} / \mathrm{kg}$ once daily). The distribution of HDL particle size was also modified after drug administration; there was a significant increase in pre-beta and alpha HDL particles. In a cell culture model, RVX 208 significantly increased the ability of serum to promote cholesterol efflux via ABCA1, ABCG1, or SR-BI-dependent pathways. ${ }^{[23,24]}$

\section{References}

1. Resverlogix Corp. RVX-208 Exploratory Study Illustrates Early Potential for Alzheimer's Disease. www.resverlogix.com, 10 Nov 2008 Media Release

2. Resverlogix Corp. Resverlogix Phase 1b/2a Study Meets Primary Endpoint. www.resverlogix.com, 25 Aug 2009 Media Release

3. Resverlogix Corp. Resverlogix Corp. Announces International Research Collaboration Program With Cedars-Sinai Medical Center and Atherosclerosis Researcher Dr. Prediman K. Shah. www.resverlogix.com, 26 Jan 2005 Media Release

4. Resverlogix Corp. Breakthrough in Apo AI Research: Resverlogix Expands NEXVAS Program Into Acute Coronary Market. www.resverlogix.com, 11 Jul 2005 Media Release

5. Resverlogix Corp. Resverlogix Corp. Establishes Subsidiary: RVX Therapeutics Inc. www.resverlogix.com, 29 Jul 2005 Media Release

6. Clinical Trials Insight: 700029318 Clinical Trial Profile

7. Resverlogix. Resverlogix ASSERT Trial Data Illustrates Potential for RVX-208 in Alzheimer's Disease. www.resver logix.com, 25 Jan 2011 Media Release

8. Phase II Multi-center, Double-blind, Randomized, Parallel Group, Placebo-controlled Clinical Trial for Dose-finding and Safety Study of RVX000222 in Subjects With Stable Coronary Artery Disease Clinical Trial Profile

9. Resverlogix Corp. Resverlogix Presents ASSERT Human Clinical Trial Data at the American Heart Association Late Breaker Session. www.resverlogix.com, 17 Nov 2010 Media Release

10. Resverlogix. Resverlogix Completes Dosing for ASSERT Trial. www.resverlogix.com, 12 May 2010 Media Release
11. Resverlogix Corp. Resverlogix Completes Patient Recruitment for ASSERT Trial. www.resverlogix.com, 08 Feb 2010 Media Release

12. Resverlogix Corp. Resverlogix Commences Phase 2 Atherosclerosis Clinical Trial. www.resverlogix.com, 22 Dec 2009 Media Release

13. Resverlogix Corp. Resverlogix Updates Shareholders on Accelerated Clinical Trial Plan. www.resverlogix.com, 17 Oct 2009 Media Release

14. Resverlogix Corp. Resverlogix's Phase 2 ASSURE Trial Amended. www.resverlogix.com, 10 Sep 2010 Media Release

15. Resverlogix Corp. Resverlogix Activates First Site for ASSURE 1 Clinical Trial. www.resverlogix.com, 25 Feb 2010 Media Release

16. Phase II Multi-center, Double-blind, Randomized, Parallel Group, Placebo-controlled Clinical Trials for the Assessment of Lipid and Coronary Plaque Changes With RVX000222 in Patients With Acute Coronary Syndrome Events. Clinical Trial Profile

17. Resverlogix Corp. Resverlogix Scientific Data Presented at EAS Congress. www.resverlogix.com, 22 Jun 2010 Media Release

18. Resverlogix Corp. Resverlogix RVX-208 Second Clinical Trial Demonstrates Success on Key Reverse Cholesterol Transport Markers. www.resverlogix.com, 29 Sep 2009 Media Release

19. Resverlogix Corp. Resverlogix Provides Quarterly Update. www.resverlogix.com, 28 Apr 2009 Media Release

20. Resverlogix Corp. Resverlogix Board of Directors Update 26 November 2008. www.resverlogix.com, 26 Nov 2008 Media Release

21. Resverlogix Corp. Resverlogix Advances to Second Arm of Phase 1b/2a Clinical Trial. www.resverlogix.com, 21 Oct 2008 Media Release

22. Gordon A, Jahagirdar R, Johansson J, et al. RVX-208 a small molecule that induces apolipoprotein A-I production progresses to phase $\mathrm{Ib} / \mathrm{IIa}$ clinical trials. 58th Annual Scientific Session of the American College of Cardiology: 205 abstr. 1021-74, 10 Mar 2009. Available from URL: http://www.sciencedirect.com. Canada [English]

23. Krimbou L, Jahagirdar R, Bailey D, et al. Compound RVX-208 modulates HDL-C levels and function in nonhuman primates and in early (phase I) human trials. $81 \mathrm{st}$ Annual Scientific Sessions of the American Heart Association: 371 abstr. 1696, 8 Nov 2008. Available from URL: http://scientificsessions.americanheart.org. Canada [English]

24. Resverlogix Corp. RVX-208 Data Demonstrates Increase in Functional HDL Particles. www.resverlogix.com, 10 Nov 2008 Media Release

25. Resverlogix Corp. Dosing for RVX-208 Phase la Clinical Study Completed. www.resverlogix.com, 22 Apr 2008 Media Release

26. Resverlogix Corp. Progress Report from RVX-208 Phase 1 Clinical Study. www.resverlogix.com, 14 Jan 2008 Media Release

27. Resverlogix Corp. Reverse Cholesterol Transport by RVX208 a Small Molecule for ApoA-I Production Increase Presented at American Heart Association Scientific Meeting. www.resverlogix.com, 05 Nov 2007 Media Release

28. Krimbou L, Jahagirdar R, Ruel I, et al. Oral administration of compound RVX-208 increases serum levels of ApoA-I and improves high-density lipoprotein-mediated cholesterol efflux in African green monkeys. Circulation 116: 126 , No. 16, 16 Oct 2007. Canada [English] 
29. Resverlogix Corp. Resverlogix Scientific Data Presented at ATVB Conference. www.resverlogix.com, 09 Apr 2010 Media Release

30. Resverlogix Corp. FDA Grants Resverlogix Approval to Commence a Phase 1 Clinical Trial for RVX-208. www.resverlogix.com, 10 Dec 2007 Media Release

31. Resverlogix Corp. Successful ASSERT Trial Results in Resverlogix Filing New RVX-208 Patent. www.resverlogix.com, 29 Nov 2010 Media Release
32. Wong NC, Gordon A, Johansson J, et al. RVX-208 given orally to humans raises plasma ApoA-I and HDL in a phase 1b/2a clinical trial. 59th Annual Scientific Session of the American College of Cardiology: abstr. 1164-333, 14 Mar 2010. Available from URL: http://www.abstractsonline.com. Canada [English] Clinical Trials Insight

33. Resverlogix Corp. Key Primary Resverlogix Objective Obtained. www.resverlogix.com, 18 Jun 2008 Media Release 